\title{
A Implementação de Hortas Verticais em uma Escola da Rede Pública Rural de Ensino de Cascavel-PR
}

\author{
Ana Claudia de Almeida ${ }^{1}$ \\ Luís Felipe Andrietti ${ }^{2}$ \\ Renan Marques ${ }^{3}$ \\ Juliana Moreira Prudente de Oliveira ${ }^{4}$
}

Atividades de Educação Ambiental são essenciais para a sensibilização da população e para o desenvolvimento de uma consciência ambiental crítica. A confecção de uma horta vertical com materiais reutilizáveis é uma das estratégias para o desenvolvimento da Educação Ambiental entre os alunos. Com o objetivo de formar cidadãos mais responsáveis e críticos e promover a melhoria na qualidade alimentar, o presente trabalho foi realizado com alunos de uma escola da rede pública rural no município de Cascavel, Paraná, trabalhando-se os conceitos relacionados com poluição por resíduos sólidos e alimentação saudável através da confecção de hortas verticais. As atividades desenvolvidas demonstraram que os alunos tinham algumas concepções alternativas em relação à temática ambiental apresentada, podendo ser utilizadas como forma alternativa às aulas clássicas de várias áreas das ciências e geografia e para promover a mudança de conceitos e para a construção de consciência crítica ambiental pelos alunos.

Palavras-chave: educação ambiental, recicláveis, sustentabilidade.

\section{The Implementation Of Vertical Gardens In A Rural Public School Of Cascavel-PR}

Environmental education activities are essential to develop a critical environmental awareness. The making of a vertical garden using reusable materials is one of the strategies for the development of environmental education among students. Aiming to educate people to be more responsible and critical and improves food quality, the present study was conducted with students from a rural public school in Cascavel, Paraná, working the concepts related to pollution from solid waste and healthy eating by making vertical gardens. The activities showed that the students had some alternative concepts regarding the environmental issues presented. They can be used as an alternative to classic classes in many areas of science and geography, to promote change in the wrong concepts and to build critical environmental awareness by students.

Keywords: environmental education, recyclable materials, sustainability

\footnotetext{
${ }^{1}$ Graduanda do curso de Ciências Biológicas da Universidade Estadual do Oeste do Paraná - Campus Cascavel

${ }^{2}$ Graduando do curso de Ciências Biológicas da Universidade Estadual do Oeste do Paraná - Campus Cascavel

${ }^{3}$ Graduando do curso de Ciências Biológicas da Universidade Estadual do Oeste do Paraná - Campus Cascavel

${ }^{4}$ Docente do curso de Ciências Biológicas da Universidade Estadual do Oeste do Paraná - Campus Cascavel
} 


\section{Introdução}

A preocupação com o meio ambiente tem crescido muito nos últimos anos, principalmente após a Cúpula da Terra (ECO-92 ou RIO-92), realizada no Rio de Janeiro em 1992. Essa reunião teve como objetivo o levantamento das questões de combate à pobreza, mudança nos padrões de consumo, crescimento populacional, saúde, poluição, emissão de gases do efeito estufa, combate ao desflorestamento, conservação da diversidade biológica, desenvolvimento sustentável, entre outros, sendo desenvolvida a Agenda 21 Global. Mais recentemente, com a Rio+20, realizada no Rio de Janeiro em 2012, houve o resgate desses temas e a reformulação das estruturas para promover a redução da pobreza, a eficiência econômica, o desenvolvimento sustentável e a preservação do meio ambiente (UNCED, 1992; UNCSD, 2012).

Algumas das áreas de programas descritas na Agenda 21 Global incluem a Educação Ambiental como base fundamental na promoção do desenvolvimento sustentável, tanto no ensino formal como informal (UNCED, 1992). No âmbito nacional, a aprovação da Lei ${ }^{\circ}$ 9.795, de 27 de Abril de 1999, que instituiu a Política Nacional de Educação Ambiental (PNEA), foi de extrema importância para que a Educação Ambiental fosse incorporada nas escolas. Conforme esta lei (BRASIL, 1999), os processos pelos quais "o indivíduo e a coletividade constroem valores sociais, conhecimentos, habilidades, atitudes e competências voltadas para a conservação do meio ambiente, bem de uso comum do povo, essencial à sadia qualidade de vida e sua sustentabilidade" constituem a Educação Ambiental, sendo esta componente essencial e permanente da educação nacional, presente em todos os níveis e modalidades do ensino e direito de todos os cidadãos brasileiros.

Atividades de Educação Ambiental, portanto, são essenciais para a sensibilização da população e desenvolvimento de uma consciência ambiental, obtida através da "Educação Ambiental crítica", com problematização da realidade, de nossos valores, atitudes e comportamentos na forma de diálogo, reflexão e ação no mundo (LOUREIRO, 2007).

Uma das questões que pode ser trabalhada na Educação Ambiental é a reutilização de diversos materiais, associada à saúde, à promoção de hábitos alimentares saudáveis e à garantia de acesso ao alimento por famílias de baixa renda. Segundo Cribb (2010), a confecção de hortas verticais utilizando-se garrafas PET e embalagens Tetra Pak pode ser uma maneira de reduzir os impactos ambientais gerados pelos resíduos sólidos. A autora ainda ressalta que esse pode ser um projeto para sensibilização da população sobre os efeitos negativos desses resíduos no meio ambiente, promoção do acesso à alimentação saudável e 
contribuição por meio da colaboração, do trabalho em equipe, da percepção da importância do cuidado e do senso de responsabilidade, para a aquisição de novos valores e novas formas de pensar. Lima et al. (2013) e Taham et al. (2015) reforçam que é uma atividade de baixo custo, podendo ser implantada em pequenos espaços, como em casas e escolas que não possuem pátios para a criação de hortas comuns.

A Política Nacional de Resíduos Sólidos (BRASIL, 2010), instituída pela Lei $\mathrm{n}^{\circ}$ 12.305, de 2 de Agosto de 2010, apresenta como um de seus instrumentos a Educação Ambiental, além de conter entre os seus objetivos a não geração, redução, reutilização, reciclagem e tratamento de resíduos sólidos. A questão dos resíduos sólidos possui relação direta com a qualidade de vida da população, com a sustentabilidade, através do consumo responsável, e com a qualidade ambiental, através da sua destinação final adequada (ANDREOLI, 2015). Ainda conforme essa lei, podemos destacar o plano de gestão municipal integrada de resíduos sólidos, que inclui o desenvolvimento de programas e ações de Educação Ambiental com os mesmos objetivos acima citados (BRASIL, 2010). Portanto, a horta vertical confeccionada com materiais reutilizáveis se torna uma ferramenta importante para promover a Educação Ambiental nas escolas.

Há alguns incentivos governamentais que auxiliam a implementação da Educação Ambiental nas escolas, como é o caso do Programa Mais Educação, instituído pela Portaria Interministerial nº 17/2007 e regulamentado pelo Decreto 7.083/10, que, através da Educação Integral, permite às escolas realizar, além de outras atividades, ações na Educação Ambiental (BRASIL, 2016). Um dos temas abordados pelo Programa Mais Educação é o projeto "Horta Escolar: Enriquecendo o Ambiente Estudantil", que buscou mostrar às comunidades a importância dos produtos provenientes de recursos naturais, que visa à alimentação saudável e procura sensibilizá-las quanto às questões referentes à Educação Ambiental (PEREIRA et al., 2012). Dentre os temas de possível abordagem, com a confecção das hortas verticais, estão a fotossíntese, a alimentação saudável, a pirâmide alimentar, a conservação de alimentos, a sustentabilidade, o cultivo orgânico (ESTEVAM et al., 2013; GOMES; OLIVEIRA, 2015), a morfologia vegetal, o solo e organismos vivos presentes no mesmo, bem como o uso de materiais reutilizáveis, a redução da poluição do solo e da água com resíduos sólidos e com o uso de agrotóxicos e seus efeitos na saúde humana.

Alguns efeitos podem ocorrer de forma indireta e também serem positivos na criação de uma horta vertical, como o embelezamento do local, a redução de poluição visual e estabelecimento de conforto visual para quem utiliza o espaço, o retorno para a sala de aula de Revista Extensão em Foco, nº 13, Jan/ Jul (2017) p. 64 - 77. 
alunos mais calmos e o despertar do interesse pelos alimentos cultivados nas hortas (MELO et al., 2016).

Alguns trabalhos têm mostrado a motivação dos alunos para a confecção da horta vertical por estimular a criatividade e sair da rotina da sala de aula (FERREIRA, 2012; BENETATI, 2014; LIMA et al., 2014). Além disso, essa atividade oferece benefícios ambientais e econômicos, ao diminuir os gastos com tratamento e disposição final desses resíduos (LIMA et al., 2014). O projeto também pode ser autossustentado pelos alunos e professores da escola, oferecendo recursos para a merenda escolar, sem necessidade de ter alguém de fora da escola para mantê-lo.

O consumo de hortaliças por habitante no Brasil é muito baixo quando comparado com diversos países da Europa e Ásia, por exemplo, sendo que fatores como preço, costume e falta de produtos de qualidade contribuem para isso (FERNANDES, 2007). Segundo Barbosa e Silva (2007), estimam-se que em torno de $15 \%$ das crianças brasileiras apresentam obesidade. Nesse contexto, a escola tem um papel fundamental na promoção de hábitos saudáveis. A Lei Normativa n ${ }^{\circ}$ 3.695/05 estabelece que as cantinas escolares devam contribuir para a promoção de uma alimentação saudável na escola, sendo administradas por profissionais da área de nutrição, proibidas de vender frituras e doces e incentivar a venda de frutas in natura (BARBOSA; SILVA, 2007).

A melhoria da qualidade da alimentação, tanto na escola quanto no ambiente familiar, por meio do uso de materiais de baixo custo tem efeito positivo direto sobre as comunidades de baixa renda, sendo uma técnica condizente com o desenvolvimento sustentável. Segundo Borba et al.(2013), ao produzirmos nosso alimento, nos tornamos autossuficientes, produzimos sem nenhuma intervenção química e sem destruir a ecologia dos ecossistemas, garantindo nossa segurança alimentar. Além disso, promover atividades de interação dos alunos com o meio ambiente e construir pequenas áreas verdes faz com que o aluno se aproxime e concretize a interação com o meio ambiente de forma lúdica, funcionando como recurso educacional para alcançar diferentes objetivos e permitir que o aprendizado se torne mais claro e real (SILVEIRA; HOLANDA, 2014).

A reutilização de materiais também afeta de forma direta o meio ambiente, já que muitos destes materiais causam impacto negativo no solo, na água e também na saúde pública. Um exemplo é a garrafa PET, material comumente jogado nos rios e riachos, ruas, praças públicas entre outros locais, consistindo abrigo para roedores, focos de reprodução do Aedes aegypti e outros, porém, quando reutilizadas, as garrafas PET apresentam-se como Revista Extensão em Foco, nº 13, Jan/ Jul (2017) p. 64 - 77. 
importantes aliadas na redução da poluição ambiental (BORBA et al., 2013).

O envolvimento de professores, pais e equipe pedagógica com os alunos através da reflexão, do diálogo e do trabalho em equipe é essencial para a formação de consciência crítica (GOMES; OLIVEIRA, 2015) não só dos alunos, mas de todos os participantes do projeto, além de despertar valores sociais como participação, relação interpessoal, senso de responsabilidade e sensibilização quanto ao meio ambiente, tornando-se possível o desenvolvimento de um processo de ensino-aprendizagem adequado ao contexto social em que vivem (PEREIRA et al., 2012).

As atividades de confecção de uma horta vertical com materiais reutilizáveis são de grande importância para o desenvolvimento da Educação Ambiental entre alunos em situação de baixa renda e para a promoção de melhoria da qualidade alimentar tanto dos alunos quanto de suas famílias. Sendo assim, o presente trabalho teve como propósito abordar assuntos relacionados com poluição por resíduos sólidos e alimentação saudável através da confecção de hortas verticais, procurando formar cidadãos mais responsáveis e críticos por meio da compreensão de conceitos e reutilização de materiais e melhorando a qualidade da alimentação dos alunos de uma escola da rede pública de ensino.

\section{Materiais e métodos}

O projeto relatado neste trabalho foi elaborado e desenvolvido durante as disciplinas de Teoria e Prática de Ensino de Ciências e Biologia I e $\mathrm{II}^{5}$ do $2^{\circ}$ e $3^{\circ}$ ano, respectivamente, do Curso de Ciências Biológicas - Licenciatura da Universidade Estadual do Oeste do Paraná (UNIOESTE) e implementado em uma escola da rede rural de ensino localizada no município de Cascavel, Paraná. As atividades foram realizadas dentro do Projeto Integrador de Agrociências ${ }^{6}$, promovido pelo Núcleo Setorial Agrícola, envolvendo 17 alunos do $9^{\circ}$ ano do Ensino Fundamental e $1^{\circ}, 2^{\circ}$ e $3^{\circ}$ anos do Ensino Médio, com duração de 4 horas/aula.

Primeiramente, foi realizada uma aula dinâmica com os alunos, abordando assuntos relacionados à poluição por resíduos sólidos e sustentabilidade, discutindo com os alunos questões sobre os temas. Além disso, foi abordado o tema "horta vertical" como alternativa

\footnotetext{
${ }^{5}$ As disciplinas citadas fazem parte das que contemplam a dimensão prática ainda nos primeiros anos do curso, sendo que nestas, isto é realizado principalmente por meio da inserção dos acadêmicos no ambiente escolar mediante o desenvolvimento de projetos.

${ }^{6}$ O Projeto Integrador de Agrociências é uma disciplina que envolve os alunos do $9^{\circ}$ ano do Ensino Fundamental e dos $1^{\circ}, 2^{\circ}$ e $3^{\circ}$ anos do Ensino Médio. As aulas são realizadas uma vez por semana, durante duas horas/aula, nas quais os alunos discutem temas e desenvolvem atividades relacionadas ao ambiente rural.

Revista Extensão em Foco, nº 13, Jan/ Jul (2017) p. 64 - 77.
} 
para a reutilização de resíduos recicláveis, redução da poluição por resíduos sólidos, melhoria na qualidade alimentar, reduzindo a utilização de agrotóxicos na alimentação in natura dos alunos do projeto e relacionando estes conteúdos ao seu cotidiano. As atividades com os alunos envolveram perguntas e apresentação de vídeo informativo sobre tipos de lixo. Os alunos foram questionados sobre que tipo de poluição mais afeta o meio ambiente e também se eles conheciam a quantidade de lixo produzida por uma comunidade, com destaque para a poluição visual, pedindo para imaginarem como seria o ambiente escolar se não houvesse destinação adequada dos resíduos sólidos. Foi introduzida a Resolução CONAMA no 275/2001 aos alunos, sendo demonstrada, por meio de imagens ilustrativas, a tipologia de cores para os coletores de resíduos, descritos na lei.Neste contexto, foram apresentados alguns tipos de resíduos recicláveis (lata, garrafa PET, papel, vidro) e foi apontado, mediante a interação palestrante-aluno, o tempo de decomposição de cada um dos resíduos acima citados e, como uma alternativa à destinação inadequada de resíduos, foi introduzido os conceitos de sustentabilidade e dos 4 R's (Repensar, Reduzir, Reutilizar e Reciclar).

O aterro sanitário fez parte da apresentação, sendo destacada a sua vida útil e a dificuldade de gestão após esse período, visto a produção de substâncias tóxicas, dentre eles os diversos gases resultantes da decomposição de material orgânico.

Outro ponto trabalhado foi a poluição por agrotóxicos quando os galões não são descartados corretamente, além do uso indevido deles. Neste momento, foram apresentados vídeos sobre sustentabilidade e reutilização, reciclagem e uso do adubo orgânico na horta. Relacionando-se a essa abordagem, foi introduzido o conceito de horta vertical com garrafas PET como forma de reutilização de materiais e redução de resíduos sólidos no ambiente. A primeira aula foi finalizada com a confecção de cartazes sobre o tema apresentado pelos alunos que, em grupos, tiveram a oportunidade de expressar o conhecimento construído, a criatividade e a cooperação entre si. Para a aula seguinte, ficou firmado o compromisso de que os alunos trariam para a próxima aula garrafas pet para a confecção da horta vertical.

Posteriormente, foi realizada a confecção da horta vertical pelos alunos, promovendo tanto a autonomia durante a produção da sua própria horta quanto o trabalho em equipe ao auxiliar os demais colegas. Para esta etapa, foram utilizadas garrafas PET, terra adubada, mudas (repolho, alface, rúcula, salsinha e cebolinha), varal e tesoura.

O modo de preparo da horta foi realizado da seguinte maneira: (i) corte das garrafas e perfuração das mesmas para passagem do varal; (ii) plantio das mudas; (iii) fixação das garrafas em uma das paredes da escola (próxima da cozinha para facilitar o acesso pelas Revista Extensão em Foco, nº 13, Jan/ Jul (2017) p. 64 - 77. 
cozinheiras); (iv) primeira rega das plantas.

A participação dos alunos durante as aulas (discussões e envolvimento dos alunos nas atividades propostas) foram avaliadas de forma qualitativa através da observação (MARCONI; LAKATOS, 2003; FLICK, 2009).

\section{Resultados e discussão}

Diversos projetos desenvolvidos nas escolas com o propósito de trabalhar a Educação Ambiental envolvem como tema central os resíduos produzidos pelo homem, ou seja, o "lixo" (CASTOLDI et al., 2009), que, atualmente, é um dos maiores problemas ambientais que a sociedade humana enfrenta, principalmente quanto à disposição final correta dos resíduos sólidos (NETO; COLESSANTI, 2005).

Em um estudo realizado por Neto e Colessanti (2005) em turmas da $5^{\text {a }}$ série de uma escola pública municipal, 59\% dos alunos possuíam uma concepção de que "lixo" são restos que não servem para nada, é sujeira, $23 \%$ responderam que é o material que o homem joga no chão, nas ruas e não utiliza mais e, apenas 15\% relacionou o "lixo" a materiais que podem ser reaproveitados ou reciclados. Correia et al. (2016) apontam que o tema reciclagem, apesar de ser muito trabalhado, tanto nas escolas quanto pela mídia, ainda não está relacionado com a realidade percebida pelos alunos. Entretanto, no presente estudo, após serem questionados sobre quais tipos de resíduos existem, podemos perceber que há uma percepção maior sobre o que o ser humano produz de resíduo e como é categorizado. Dentre as respostas dos alunos, estavam os resíduos orgânicos, como "restos de comida", "fezes de animais", recicláveis, como "metal, vidro, papel e plástico", hospitalares, como "seringas" e "agrícolas, no caso dos insumos". Portanto, os alunos conseguiram perceber que, além do resíduo orgânico, que normalmente são entendidos como restos que não possuem mais proveito, existem os resíduos que podem ter alguma função posterior ao seu uso, que é o caso dos recicláveis. Após a apresentação do vídeo que mostra os diferentes tipos de lixo citados pelos alunos, que puderam identificar os resíduos orgânicos (casca de banana), recicláveis (latinha), resíduos agrícolas (com destinação inadequada de galões de agrotóxico) e hospitalares, os palestrantes acrescentaram ainda outros tipos de resíduos como o resíduo resultante de processos nucleares e os resíduos resultantes de processos industriais.

Em relação à pergunta sobre o tipo de poluição que mais afeta o meio ambiente, alguns alunos responderam que "a poluição por carros e fábricas, que jogam gás carbônico no

Revista Extensão em Foco, nº 13, Jan/ Jul (2017) p. 64 - 77. 
ar" parece ser a mais agressiva, ficando evidente que, mesmo com a discussão inicial sobre os perigos do resíduo sólido, os mesmos não o veem como um grande problema ambiental, demonstrando, assim, a forte influência de seus conceitos prévios a respeito da poluição.

Cruz e Bareiro (2013), em seu trabalho com percepção ambiental sobre os efeitos da poluição por alunos do $9^{\circ}$ ano de uma escola de Curitiba, verificaram que em $79 \%$ das respostas sobre os principais poluidores do meio ambiente encontravam-se os moradores, sendo que em apenas $20 \%$ das respostas encontravam-se as indústrias. Os autores também mostram que, dentre os alunos que sentiam algum incômodo com aspectos relacionados ao meio ambiente no bairro onde moravam e, consequentemente, da escola, apenas $13 \%$ foi referente à poluição por carros. Essas respostas estão associadas principalmente aos resíduos sólidos: os alunos têm a percepção de que os moradores são os principais responsáveis pela poluição por produzir muito "lixo", o que não ocorreu entre os alunos do presente estudo.

Ainda sobre a percepção sobre a poluição, Voichicoski e Morales (2010) demonstraram que entre alunos do $9^{\circ}$ ano de uma escola do município de Palmeira, PR, 35\% acreditam que a responsabilidade pelas questões ambientais não são dos alunos, já que as indústrias poluem muito mais, evidenciando que a concepção de que a poluição por outros resíduos que não os sólidos produzidos pela população em geral são os principais problemas ambientais relacionados ao tema é encontrada em grande porcentagem dos alunos, o que também ficou evidente neste trabalho.

Em relação à quantidade de resíduos que são produzidos na cidade e no campo e como este afeta o meio ambiente, os alunos ficaram apreensivos e responderam que "o lixo pode poluir o solo e a água”. Os palestrantes acrescentaram a esta resposta a poluição visual e, para que a ênfase fosse maior, foi sugerido um cenário onde a escola na qual estava sendo aplicada a experiência estivesse repleta de "lixo", na hipótese de que todo o "lixo" produzido não fosse destinado corretamente e se acumulasse no ambiente escolar. Os mesmos constataram que o fato seria desagradável. Neste ponto, foi destacado que o acúmulo de resíduos em um determinado local pode atrair animais indesejados como ratos, moscas e baratas e que os mesmos são vetores de doenças, utilizando como exemplo o fato histórico da pandemia da peste bubônica na Idade Média.

Para uma contextualização com o ambiente de produção no campo, no qual os alunos estão inseridos, foi apontada a poluição produzida pela disposição inadequada de embalagens de garrafas de agrotóxico, destacando-se que os mesmos causam poluição no solo, na água e nos alimentos, além de ser responsável pela redução da biodiversidade, que muitas vezes é Revista Extensão em Foco, nº 13, Jan/ Jul (2017) p. 64 - 77. 
benéfica ao produtor; fato que tem ocorrido nos arredores do assentamento, onde os produtores em larga escala usam agrotóxicos, causando diversas alterações na saúde dos moradores. Para que isso não ocorra dentro do assentamento, vários produtores estão sendo introduzidos ao conceito de cultivo orgânico, além da formação de barreiras verdes separando as fazendas do assentamento. Essa relação da agricultura com uso de agrotóxicos, bem como sua disposição inadequada, é de grande importância para a melhora da percepção e compreensão da poluição causada por esses insumos (OLIVEIRA et al., 2013).

Aos alunos, foram apresentados alguns materiais recicláveis, com posterior desafio de dedução do tempo de decomposição dos mesmos. Constatou-se, então, que os alunos não apresentavam conhecimento sobre o tema, pois deram respostas muito diferentes do período real. Para outros materiais, não souberam responder. Por essa razão, houve a explanação a respeito dos reais tempos de decomposição de cada um dos resíduos, desde os recicláveis a borracha e outros. Conhecer a duração da biólise dos materiais auxilia na compreensão de que, mesmo que eles se decomponham, o processo é lento e se produzirmos muitos resíduos todos os dias, não haverá espaço o suficiente para seu armazenamento até completa degradação. Além disso, se dispostos de forma inadequada, o processo de decomposição gera diversos gases que afetam a saúde humana e do meio ambiente (SOUZA et al., 2013). Foi apresentado, também, o termo sustentabilidade, o qual os alunos disseram nunca ter ouvido falar e, portanto, não sabiam o significado. Em decorrência disto, foi apresentado o conceito e quais ações possibilitam a sustentabilidade, como redução do desperdício de água e alimento, uso consciente dos recursos naturais (solo, água, animais, plantas), distribuição uniforme do alimento produzido, levando em consideração que para a produção deste é necessário o desmatamento de muitos hectares, demonstrando também que existe um excedente de produção e que o problema não está na produção em si, mas na distribuição desordenada. Portanto, produzir de maneira sustentável é produzir de forma a atender às necessidades desta geração sem que as próximas gerações sejam afetadas pelos meios de cultivo desta (WCED, 1987). A compreensão sobre sustentabilidade é muito importante para o desenvolvimento de uma percepção sobre a poluição ambiental. Castoldi et al. (2009) mostram que 24\% dos alunos do $3^{\circ}$ ano do ensino médio de escolas estaduais do município de Cascavel, PR não acreditam que o planeta tem condições de se sustentar com os atuais níveis de poluição, compreendendo que há a necessidade de mudanças de atitude frente à poluição e consumo inconsciente dos recursos naturais.

Revista Extensão em Foco, nº 13, Jan/ Jul (2017) p. 64 - 77. 
O conceito dos 4 R's da sustentabilidade foi também um tema importante na interação realizada entre alunos e palestrantes, pois eles já tinham ouvido falar nos 3 R's (Reduzir, Reutilizar e Reciclar). Sendo assim, a proposta foi montar juntamente com os alunos um significado para o quarto R (Repensar) e, sem muita dificuldade, eles concluíram corretamente os conceitos.

Após as explicações, os alunos confeccionaram a horta vertical com auxílio dos autores deste trabalho (Figura 1), com a oportunidade de cooperação entre si e autonomia na escolha das mudas que desejariam plantar nas suas próprias hortas. Os alunos demonstraram grande interesse na atividade e concluíram que levariam a estratégia para suas casas e para o seu dia-a-dia. As atividades propostas podem ser uma alternativa às aulas clássicas de diversos conteúdos como ciências ambientais, botânica, zoologia, ecologia, espaço e até produções textuais, trabalhando-se a interdisciplinaridade. Entretanto, a manutenção da horta pela escola foi trabalhosa, o que motivou a direção e os professores a realizarem o manejo de um espaço atrás da escola para desenvolver uma horta horizontal, transferindo as mudas da horta vertical para esta, onde a manutenção se tornaria mais fácil. Além disso, os alunos levaram algumas garrafas PET com as mudas para suas casas e, manifestaram ainda, que adaptariam a ideia para outras possibilidades, como a construção de jardins. Assim, mesmo não tendo continuidade do projeto da horta vertical na escola, esta proposta despertou a comunidade escolar para as questões ambientais envolvidas, desencadeando inclusive a construção de uma horta horizontal permanente e uma maior reutilização de garrafas PET tanto da forma proposta como de outras.

Revista Extensão em Foco, nº 13, Jan/ Jul (2017) p. 64 - 77. 


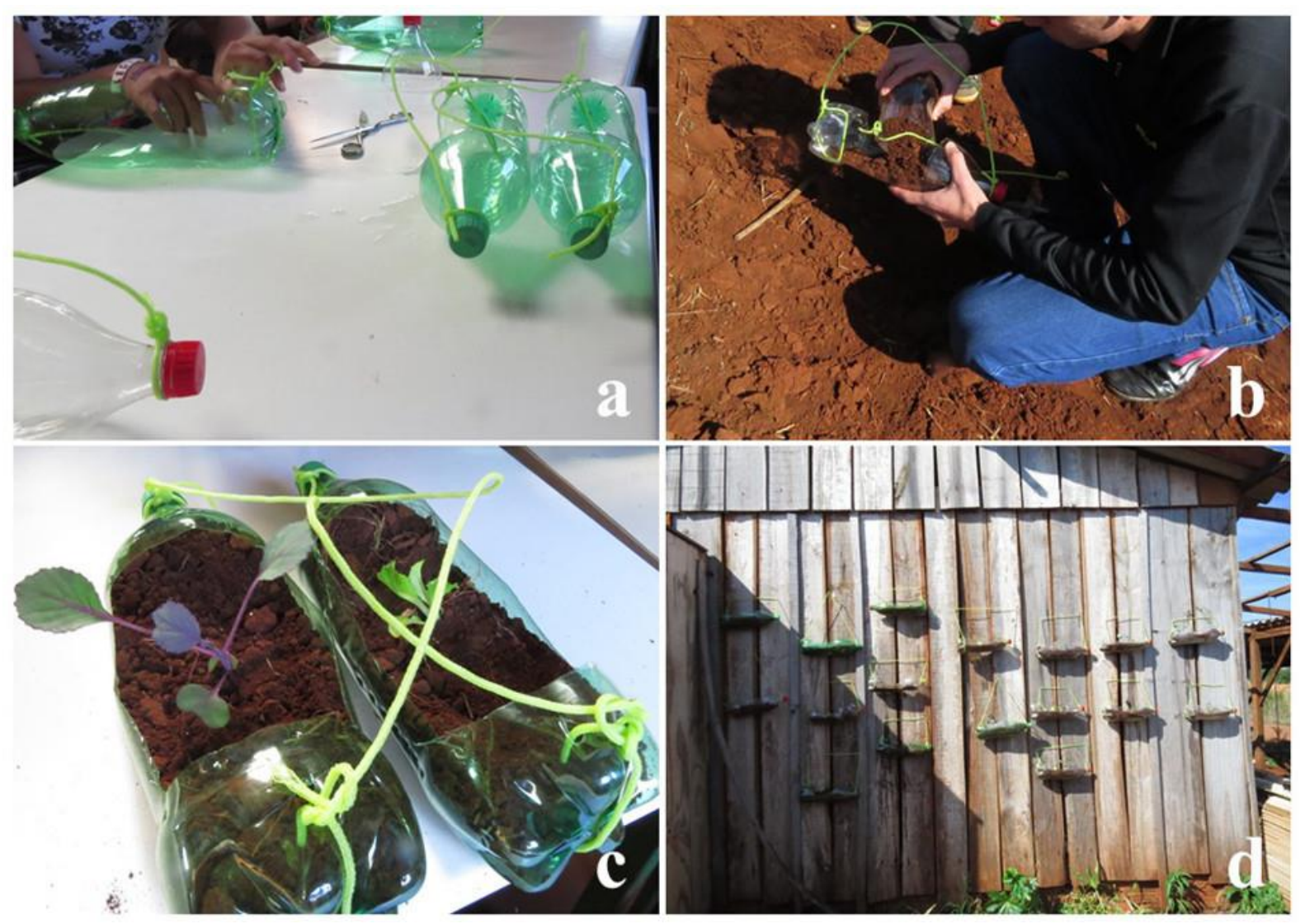

Figura 1. Confecção da horta vertical por alunos do Projeto Integrador de Agrociências de uma escola rural da rede pública de ensino no município de Cascavel, PR. Legenda: (a) corte e preparo das garrafas PET; (b) colocação da terra nas garrafas PET; (c) plantio das mudas de hortaliças na escola; (d) horta vertical finalizada. Fotos: ALMEIDA, A. C.

\section{Conclusões}

As atividades desenvolvidas demonstraram que os alunos da escola estadual em que o projeto foi desenvolvido tinham alguns conceitos alternativos em relação à temática ambiental apresentada e não conheciam o tema sustentabilidade, mesmo estando em uma escola rural. A metodologia de interação aluno-palestrante-objeto de estudo permitiu que os alunos compreendessem os conceitos trabalhados, podendo ser utilizada para promover a mudança de conceitos e para a construção de consciência crítica ambiental.

As discussões em sala de aula permitiram aos alunos o desenvolvimento da competência de expressão e comunicação, participando e posicionando-se criticamente frente aos problemas propostos. Além disso, integrar o tema no cotidiano deles facilitou a aprendizagem e apreensão de conceitos, como, por exemplo, quanto aos resíduos sólidos provenientes do uso dos agrotóxicos e como isso afeta negativamente o ambiente rural. Ainda, o trabalho em grupo permitiu o desenvolvimento da cooperação e socialização entre os 
alunos.

Com a construção da horta vertical, pode-se perceber que para o ensino de ciências ambientais e da saúde, a dinâmica do trabalho participativo em sala de aula somada à atividade prática resultou em um maior interesse por parte dos alunos, facilitando, assim, o aprendizado. Além disso, esse tipo de estratégia apresenta-se como uma ferramenta importante para o professor ao lidar com concepções alternativas e com a sensibilização quanto às problemáticas tratadas neste trabalho.

Ademais, a execução deste trabalho, ao aproximar os acadêmicos da realidade de uma escola, nesse caso rural, permitiu que estes relacionassem teoria e prática, vivenciando possibilidades e desafios, a fim de desenvolverem competências e habilidades para o exercício da profissão de professor.

\section{Referências}

ANDREOLI, C. V.; ANDREOLI, F. N.; TRINDADE, T. V.; HOPPEN, C. Resíduos sólidos: origem, classificação e soluções para destinação final adequada. Coleção Agrinho, p. 531$552,2015$.

BARBOSA, A. C.; SILVA, V. Alimentação saudável na escola: Lei n 3965. Jornal Escola Saudável, n. 4, 2007.

BENETATI, L. A jardinagem como educação ambiental na escola. 2014. 36 f. Monografia de Especialização (Ensino de Ciências). Universidade Tecnológica Federal do Paraná, Medianeira, 2014.

BORBA, S. N. S.; VARGAS, D. L.; WIZNIEWSKY, J. G. Promovendo a educação ambiental e sustentabilidade através da prática da agricultura de base ecológica. Revista Eletrônica do Curso de Direito da UFSM, v. 8, p. 631-639, 2013.

BRASIL. Lei n ${ }^{\circ}$ 9.795, de 27 de Abril de 1999. Dispõe sobre a educação ambiental, institui a Política Nacional da Educação Ambiental e dá outras providências. Diário Oficial da União. Brasília, 1999. Disponível em: 〈http://www.planalto.gov.br/ccivil_03/leis/L9795.htm>. Acesso em: 02 jun. 2016.

BRASIL. Lei $\mathrm{n}^{\circ}$ 12.305, de 2 de Agosto de 2010. Institui a Política Nacional de Resíduos Sólidos; altera a Lei $\mathrm{n}^{\circ}$ 9.605, de 12 de fevereiro de 1998; e dá outras providências. Diário Oficial da União. Brasília, 2010. Disponível em: < http://www.planalto.gov.br/ccivil_03/_ato2007-2010/2010/lei/112305.htm>. Acesso em: 02 jun. 2016.

BRASIL. Ministério da Educação. Programa Mais Educação. Disponível em: <http://portal.mec.gov.br/programa-mais-educacao >. Acesso em: 02 jun. 2016.

CASTOLDI, R.; BERNARDI, R.; POLINARSKI, C. A. Percepções dos problemas ambientais por alunos do ensino médio. Revista Brasileira de Ciência, Tecnologia e Sociedade, v. 1, n. 1, p. 56-80, 2009.

Revista Extensão em Foco, nº 13, Jan/ Jul (2017) p. 64 - 77. 
CONAMA Conselho Nacional do Meio Ambiente. Resolução CONAMA no 275, de 25 de abril de 2001. Estabelece o código de cores para os diferentes tipos de resíduos, a ser adotado na identificação de coletores e transportadores, bem como nas campanhas informativas para a coleta seletiva. Diário Oficial da União. Brasília, 2001. Disponível em: 〈http://www.mma.gov.br/port/conama/legislacao/CONAMA_RES_CONS_2001_275.pdf $>$. Acesso em: 19 jul. 2016.

CORREIA, J. N.; FIGUEIREDO-DE-ANDRADE, C. A.; LIMA, N. B. Lixo e reciclagem: a percepção ambiental de estudantes de escolas públicas e privadas do município de Bom Jesus do Itabapoana (RJ). Perspectivas online: Ciências Humanas e Sociais Aplicadas, v. 15, n. 6, p. 53-65, 2016.

CRIBB, S. L. S. P. Contribuições da educação ambiental e horta escolar na promoção de melhorias ao ensino, à saúde e ao ambiente. Revista Eletrônica do Mestrado Profissional em Ensino de Ciências da Saúde e do Ambiente, v. 3, n. 1, p. 42-60, 2010.

CRUZ, A. G.; BAREIRO, E. A percepção ambiental sobre os efeitos da poluição pelos alunos do ensino fundamental do bairro Santa Quitéria - Curitiba/PR. In: SIMPÓSIO DE ESTUDOS URBANOS, 2. A DINÂMICA DAS CIDADES E A PRODUÇÃO DO ESPAÇO. Anais do II Simpósio de Estudos Urbanos. Campo Mourão: UNESPAR, 2013, p 1-18.

ESTEVAM, P. M. S.; ARDENGUI, A. A. F.; ACRANI, S. Construção de horta vertical na escola, uma ferramenta didática para o ensino de biologia. Revista Encontro de Formação de Professores, v. 1, n. 1, p. 1-5, 2013.

FERNANDES, M. C. A. Orientações para implantação e implementação da horta escolar. Caderno 2: A horta escolar como eixo gerador de dinâmicas comunitárias, educação ambiental e alimentação saudável e sustentável. Brasília: Ministério da Educação, 2007.

FERREIRA, E. A. Horta vertical na escola. 2012. 31 f. Monografia de Especialização (Ensino de Ciências). Universidade Tecnológica Federal do Paraná, Medianeira, 2012.

FLICK, U. Introdução à pesquisa qualitativa. 3 ed. Porto Alegre: Artmed, 2009.

GOMES, L. M. J. B.; OLIVEIRA, S. M. S. Da luz à mesa: o ano internacional da agricultura familiar na escola. Revista Práxis, v. 7, n. 14, p. 57-62, 2015.

LIMA, A. F. P.; JOSÉ, B. R.; FIALHO, F. A. N.; PCHARA, F. R. F.; MOTA, J. P.; BLUM, M. N.; PCHARA, M. R. F.; MILLER, P. R. M. Subsídios à aquicultura urbana a partir da produção integrada de peixes, hortaliças, minhocas e macrófitas em sucata de geladeiras. Anais da XI Reunião Científica do Instituto de Pesca. São Paulo: Secretaria de Agricultura e Abastecimento, 2013, p. 1-3.

LIMA, A. S. D.; DUARTE, K. L. S.; ARAÚJO, E. P. Confecção de uma horta vertical utilizando garrafa PET na Escola Estadual Clóvis Pedrosa, Cabaceiras-PB. Anais do V Congresso Brasileiro de Gestão Ambiental. Belo Horizonte: IBEAS, 2014, p. 1-6.

LOUREIRO, C. F. A questão ambiental no pensamento crítico: natureza, trabalho e educação. Rio de Janeiro: Quartet, 2007.

MARCONI, M. A.; LAKATOS, E. M. Fundamentos de metodologia científica. 5 ed. São Paulo: Atlas, 2003.

MELO, E. F. R. Q.; GIGLIOLI, A.; PIRES, T. B. Educação ambiental e reciclagem de materiais associados ao paisagismo produtivo. Anais da $\mathbf{V}$ Jornada de Extensión del Mercosur. Passo Fundo: UPF, 2016, p. 1-9.

Revista Extensão em Foco, nº 13, Jan/ Jul (2017) p. 64 - 77. 
NETO, A. T.; COLESSANTI, M. T. M. Lixo: uma palavra, vários olhares. In: Simpósio Nacional sobre Geografia, Percepção e Cognição do Meio Ambiente. Anais do Simpósio Nacional sobre Geografia, Percepção e Cognição do Meio ambiente. Londrina: UEL, 2005, p. 1-16.

OLIVEIRA, E. M.; SANTOS, W. M. B.; MORAIS, J. L.; BASSETTI, F. J.; BERGAMASCO, R. Revista Eletrônica do Mestrado em Educação Ambiental, v. 30, n. 1, p. 23-37, 2013.

PEREIRA, S. S. Gestão de resíduos de serviço de saúde e percepção ambiental: estudos de casos em unidades de saúde de Campina Grande/PB. HYGEIA, Revista Brasileira de Geografia Médica e da Saúde, v. 7, n. 12, p. 106-126, 2011.

SILVEIRA, G. T. R.; HOLANDA, D. L. Educação Ambiental para jovens e adultos: horta vertical. Percurso Acadêmico, v. 4, n. 7, 2014.

SOUZA, G. S.; MACHADO, P. B.; REIS, V. R.; SANTOS, A. S.; DIAS, V. B. Educação ambiental como ferramenta para o manejo de resíduos sólidos no cotidiano escolar. Revista Brasileira de Educação Ambiental, v. 8, n. 2, p. 118-130, 2013.

TAHAM, T.; RIECK, S. E.; MELO JR, H. B.; SILVA, A. A.; PAZ, C. F.; SANTOS, J. J. A.; SILVA, K. G.; PEREIRA, M. B.; CAVALCANTI, P. P.; OLIVEIRA, R. G. Uma experiência de vida e cidadania no Projeto Rondon: a importância da Extensão para o desenvolvimento social. Boletim Técnico IFTM, v. 1, n. 1, p. 28-35, 2015.

VOICHICOSK, M. S. R; MORALES, A. G. M. Percepção dos alunos sobre sua responsabilidade frente ao problema do lixo. In: SIMPÓSIO NACIONAL DE ENSINO DE CIÊNCIA E TECNOLOGIA, 2. Anais do II Simpósio Nacional de Ensino de Ciência e Tecnologia. Ponta Grossa: UTFPR, 2010.

UNCED. Agenda 21. In: United Nations Conference on Environment \& Development, Rio de Janeiro, 1992.

UNCSD. Rio +20. In: United Nations Conference on Sustainable Development, Rio de Janeiro, 2012.

WCED. Our common future. Report of the World Commission on Environment and Development. Oxford: Oxford University Press, 1987.

Revista Extensão em Foco, nº 13, Jan/ Jul (2017) p. 64 - 77. 